\title{
UNUSUAL PRESENTATION OF BRAINSTEM GLIOMA AS PROGRESSIVE BULBAR PALSY
}

Suma K. R1, Muddurangappa R², Srinath $\mathrm{S}^{3}$

\section{HOW TO CITE THIS ARTICLE:}

Suma K. R, Muddurangappa R, Srinath S. "Unusual Presentation of Brainstem Glioma as Progressive Bulbar Palsy". Journal of Evolution of Medical and Dental Sciences 2015; Vol. 4, Issue 30, April 13; Page: 5237-5240, DOI: $10.14260 /$ jemds/2015/766

ABSTRACT: Brain stem gliomas/astrocytomas are slowly growing tumors affecting children and young adults. They usually present with unilateral cranial nerve palsies followed by long tract signs. Here we present a case report of a 42 year old male patient, who initially presented with thyrotoxicosis and slowly progressing dysphagia, dysarthria and dysphonia with no other long tract signs, and was later found to have brain stem glioma.

KEYWORDS: Brain stem glioma, progressive bulbar palsy, thyrotoxicosis, neurogenic dysphagia.

INTRODUCTION: Gliomas/astrocytomas of the brainstem are relatively slowly growing tumors that infiltrate tracts and nuclei. They produce a variable clinical picture depending on their location in the medulla, pons or midbrain. Most often, this tumor begins in childhood (Peak age-7 yrs) and 80\% present before 21 yrs. In most patients, initial manifestation is palsy of one or more cranial nerves, usually $6^{\text {th }}$ or $7^{\text {th }}$ on one side, followed by long tract signs (hemiparesis, ataxia, paraparesis, hemisensory, gaze disorders). In some patients, long tract signs precede cranial nerve abnormalities. Headache, vomiting, papilledema may occur late in the course of the disease which is slowly progressive over years, unless there is malignant transformation/spread to meninges with death occurring within months. ${ }^{1}$

CASE HISTORY: A 45 yrs old male patient presented with gradual onset of dysphagia, especially for liquids, which was not associated with pain, but slowly progressive, over a period of one and half year. He also complained of significant weight loss from the past 6 months. On examination, he was emaciated, had resting tachycardia, fine tremors and exophthalmos (Figure 1). His thyroid function

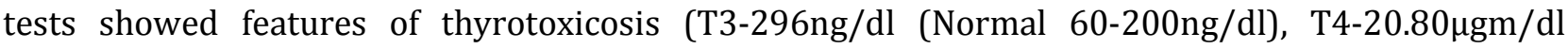
$(4.5-12 \mu \mathrm{gm} / \mathrm{dl}), \mathrm{TSH}-0.04 \mu \mathrm{IU} / \mathrm{ml}(0.3-0.5 \mu \mathrm{IU} / \mathrm{ml})$. His other hematological investigations were normal and his HIV test was negative. His upper GI endoscopy showed features of cricopharyngeal dysfunction suggesting neurogenic dysphagia. The patient was treated for thyrotoxicosis, with Carbimazole $10 \mathrm{mg}$ twice daily and beta blockers.

Over a period of next 6 to 8 months the patient developed progressive dysphagia with onset of dysarthria and nasal twang of voice. At this stage his neurological examination showed- gag reflex suppressed bilaterally, no palatal movement on 'ah' test, with uvula being central, jaw jerk was absent and he had bulbar type of dysarthria. The tongue showed no atrophy or fasciculations. Rest of the neurological examination was normal, suggesting a diagnosis of progressive bulbar palsy. His nerve conduction studies and EMG (Electromyography) was done which showed denervation changes and bilateral CPN (common peroneal nerve) axonal neuropathy, supporting the diagnosis of progressive bulbar palsy. ${ }^{2}$ 
Later over the next few months he developed mild gait ataxia, and on examination had developed brisk deep tendon reflexes and bilateral extensor plantar reflex. So he was subjected to MRI (Magnetic resonance imaging) scan of brain which showed a brain stem glioma in ponto medullary region (Figure 2, Figure 3). He received radiotherapy for the tumor, but later developed symptoms of raised intracranial pressure like headache, vomiting, and visual blurring and then died due to aspiration pneumonia.

DISCUSSION: Brainstem gliomas are uncommon in adults, and account for only 1-2\% of intracranial gliomas. Diffuse intrinsic low grade gliomas predominate in adults and $80 \%$ of them occur in ponto medullary region, with a median survival of 5 years, and malignant gliomas generally appear in patients older than 40 years. Visual disturbances, limb weakness and gait disorders are the main symptoms in majority of the cases; rare presentations include snoring, central neurogenic hyperventilation, tongue tremors, hemiparkinsonism, visual migraine auras, and pseudomyasthenic syndromes. ${ }^{3}$

In this particular patient, the brainstem glioma presented with a few atypical features. The age at presentation is unusual as it is common in children and young adults. ${ }^{4}$ The presence of thyrotoxicosis added to the confusion as to the cause of weight loss and dysphagia, as thyrotoxic myopathy is also known to cause dysphagia. ${ }^{5}$ Presence of bilateral lower cranial nerve palsy which was slowly progressive without any other neurological symptoms lead to the consideration of progressive bulbar palsy. ${ }^{6}$ Finally with the development of bilateral brisk reflexes, mild gait ataxia with extensor plantars, the evolution of the disease fit the presentation of brainstem glioma which was evident with MRI brain. Incidentally, this patient also had been exposed to ionizing radiation to the head and neck region for treatment of basal cell cancer in the pre auricular region about 20 years ago, a possibility of late effects of radiation exposure as to the cause of tumor may also be speculated.7,8

CONCLUSION: As this is a rare tumor in adults and has a varied clinical presentation it is frequently misdiagnosed in the initial stages. Radiotherapy is the standard treatment, and can improve or stabilize the patients for years. Therefore, a high index of suspicion is needed and MRI scan of brain definitely helps in early diagnosis and management of this tumour. ${ }^{9}$

\section{REFERENCES:}

1. Glioma of the brainstem, intracranial neoplasms and paraneoplastic disorders. Chapter 31. Adams and Victor's Principles of Neurology 7th edition. Maurice Victor, Allan H. Ropper. Mc Graw Hill. USA 2001 (718-719).

2. Basher Katirji. Clinical Electromyography. Chapter 35 B. Neurology in Clinical Practice, Vol 1, Principles of Diagnosis and Management.5th Edition. Walter G. Bradley, Robert B. Daroff, Gerald M. Fenichel, Joseph Jankovic. Elsevier;p- 501.

3. German Reyes-Botero, Karima Mokhtari, Nadine Martin et al. Adult brainstem gliomas, The Oncologist, vol 17(3), March 2012, p 388-397.

4. A Salmaggi, L Fariselli, I Milanesi, E Lamperti, A Silvani, A Bizzi, et al. Natural history and management of brainstem gliomas in adults. Journal of Neurology, Feb 2008, Vol 225, No 2, (171-177). 


\section{CASE REPORT}

5. Thyrotoxic Myopathy-Wikipedia, the free encyclopedia, en.wikipedia.org/wiki/Thyrotoxic Myopathy. (Accessed-14-7-2011)

6. Progressive Bulbar Palsy-Chronic Medullary Syndromes, Chapter 18, Dejong's The Neurological Examination, $5^{\text {th }}$ edition, A F Haerer. Lippincot-Raven (266-267).

7. Goodman, Brent P M, Schrader, Sara. Radiation induced cranial neuropathies manifesting as baroreflex failure and progressive bulbar impairment. Neurologist, March 2009; vol 15, issue 2(102-104).

8. 8 David N.Lois, Webster K. Cavenese. Molecular Biology of CNS Neoplasms, Neoplasms of the CNS, section 1, chapter 39.Cancer-Principles and Practice of Oncology. Vincent J. Devita. Jr, Samuel Hellman, Steven A. Rosenberg. $7^{\text {th }}$ edition. Lippincott Williams \& Wilkins, p 1827.

9. Shaheen E, Lathan, Lindsay Harle. Difficult diagnosis of brainstem glioblastoma multiforme in a woman: a case report and review of literature. Journal of Medical Case Reports 2009, 3: 87(http:/www.jmedical case reports.com/content/3/1/87).

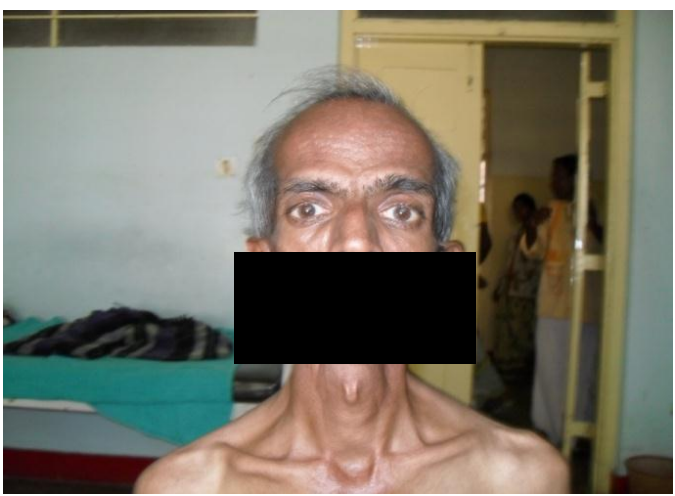

Fig. 1: Showing exophthalmos and weight loss

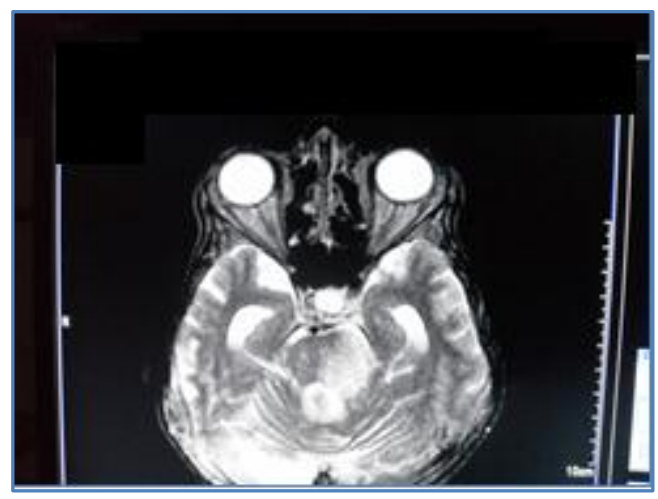

Fig. 2: T2 weighted MR Imaging of brain showing glioma in ponto medullary region

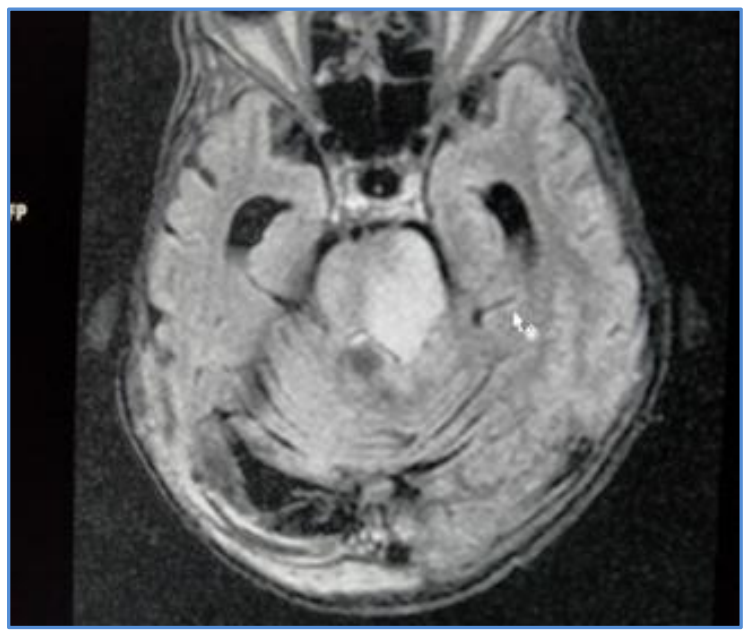

Fig. 3: T1 Weighted MR Imaging of brain showing a glioma in pontomedullary region 


\section{AUTHORS:}

1. Suma K. R.

2. Muddurangappa R.

3. Srinath S.

\section{PARTICULARS OF CONTRIBUTORS:}

1. Associate Professor, Department of General Medicine, Sri Siddhartha Medical College, Tumkur.

2. Professor, Department of General Medicine, Sri Siddhartha Medical College, Tumkur.

FINANCIAL OR OTHER COMPETING INTERESTS: None
3. Professor, Department of General Surgery, Sri Siddhartha Medical College, Tumkur.

\section{NAME ADDRESS EMAIL ID OF THE CORRESPONDING AUTHOR:}

Dr. Suma K. R, Associate Professor, Department of General Medicine, Sri Siddhartha Medical College, Agalakote, Tumkur, Karnataka, India. E-mail: drsumakr@yahoo.com

Date of Submission: 12/03/2015.

Date of Peer Review: 13/03/2015.

Date of Acceptance: 31/03/2015.

Date of Publishing: 13/04/2015. 